\title{
A participação popular na gestão local do Programa Saúde da Família em Campina Grande, Paraíba
}

\author{
William Almeida de Lacerda \\ Universidade Estadual da Paraíba (UEPB)
}

\author{
Idalina Maria Freitas Lima Santiago \\ Universidade Estadual da Paraíba (UEPB)
}

A participação popular na gestão local do Programa Saúde da Família em Campina Grande, Paraíba
Resumo: Este artigo apresenta um estudo acerca do processo de participação popular na gestão do Programa Saúde da Família (PSF),
em duas comunidades do município de Campina Grande, Paraíba, na ótica de três segmentos: conselheiros comunitários de saúde,
usuários dos grupos educativos e profissionais do Programa Saúde da Família. Visa identificar o nível de participação dos usuários
pertencentes aos grupos educativos nas atividades desenvolvidas no PSF e analisar o processo de participação dos conselheiros
comunitários de saúde na proposição, efetivação e avaliação das açães operacionalizadas pelo PSF. Os resultados indicaram um
significativo avanço no processo de participação popular na gestão das ações do programa. Porém, algumas limitações foram apresentadas:
a não participação dos conselheiros comunitários no planejamento das ações desenvolvidas pela equipe; a dificuldade do Conselho Local
de Saúde em estabelecer interlocução com os comunitários; e a falta de capacitação continuada para os profissionais em metodologias de
estímulo a participação popular. Palavras-chave: gestão, participação popular, Programa Saúde da Família.

\section{Popular Participation in Local Management of the Family Health Program in Campina Grande, Paraíba} Abstract: This article presents a study of a process of popular participation in the management of a Family Health Program in two communities in the municipality of Campina Grande, Paraíba. It examines the perspective of three segments: community health councils, users of educational groups and professionals in the Family Health Program. It strives to identify the level of participation of users of the educational groups in the activities undertaken in the Family Health Program and to analyze the participation of the community healthcare council members in proposing, enacting and evaluating the actions of the Family Health Program. A number of limitations were identified: the non-participation of the community council members in the planning of actions undertaken by the staff; the difficulty of the Local Healthcare Council in establishing interlocution with the communities; and the lack of on-going training for the professionals in methodologies to encourage popular participation.

Key words: management, popular participation, Family Health Program. 


\section{Introdução}

O presente artigo apresenta algumas contribuições para a análise do processo de participação popular na gestão local do Programa Saúde da Família (PSF) em Campina Grande, Paraíba, destacando os limites, avanços e as possibilidades que os Conselhos Locais de Saúde (CLS) e os grupos educativos, desenvolvidos no interior das Unidades Básicas de Saúde da Família (UBSF), vêm desempenhando no âmbito da gestão da política local de saúde, especificamente no tocante à participação da comunidade nas ações do PSF.

Tomamos como base para a reflexão o texto constitucional de 1988 (BRASIL, 2004) e, respectivamente, a Lei Orgânica do Sistema Único de Saúde (SUS) nos quais a participação popular é declarada como direito socialmente garantido, como um dos princípios fundantes do SUS (BRASIL, 1990), o que, sem dúvida, representou a corporificação do processo de redemocratização brasileira, não somente no âmbito da política de saúde, mas em todas as demais políticas públicas.

Entendemos que a tomada de consciência caracteriza-se como um importante elemento no processo de construção do direito à cidadania, sendo a participação popular um mecanismo preponderante para efetivação desse direito. No âmbito da saúde, tendo em vista o cenário atual em que sobressaem diversas propostas de reformas para o setor (MERHY; FRANCO, 2002), acreditamos que, apesar dos avanços legais inquestionáveis, torna-se necessário superar, ainda, vários desafios - nos planos objetivo e subjetivo - dentre os quais a construção da participação e o controle social de modo a materializar as conquistas no plano legal.

Considerando essa perspectiva, partimos da concepção de que a questão da participação popular pertence ao domínio da temática dos direitos, especialmente da construção social do direito à saúde como exercício de cidadania. O processo de construção do direito à saúde insere-se, portanto, no espaço micro das relações entre usuários, profissionais e conselheiros de saúde, imersas nos significados que aí são reproduzidos e continuamente reinterpretados. As abordagens macroestruturas, ainda que fundamentais, não se mostram suficientes para a análise desse processo por não incorporarem várias das dimensões nele envolvidas.

Nesse sentido, a intenção é fornecer elementos que permitam desvelar se o PSF vem se constituindo em uma estratégia de reestruturação da atenção básica à saúde, permitindo a efetiva participação comunitária na gestão de suas ações, ou se, ao contrário, vem reproduzindo o modelo biomédico através de ações pontuais e focalizadas junto às populações, sem considerar o aspecto da participação popular. A partir dessa problemática central, buscamos refletir algumas questões: como se dá a capacidade propositiva dos Conselhos Locais de Saúde na formulação, efetivação e avaliação das ações desenvolvidas pelo PSF? Quais as possibilidades de avanços no tocante à participação dos usuários inseridos nos grupos educativos do PSF? Como os profissionais expressam suas percepções sobre o nível de participação dos usuários inseridos nos grupos educativos e dos conselheiros de saúde nas atividades desenvolvidas pelo PSF?

A participação foi analisada no referente aos aspectos de frequiência, proposição/reivindicação, planejamento, execução e avaliação das ações desenvolvidas pelas equipes do PSF, no contexto de construção da cidadania ativa. Nessa perspectiva, Benevides (1994, p. 9) parte da concepção de que há uma cidadania passiva, aquela instituída pelo Estado, e uma cidadania ativa, fruto da conquista da sociedade civil organizada, que não só reconhece direitos e deveres, mas constrói direitos. A referida autora reforça a participação popular como fruto da cidadania ativa, quando afirma que "[...] é aquela que institui o cidadão como portador de direitos e deveres, mas essencialmente criador de direitos para abrir novos espaços de participação política."

Reportamo-nos, também, às recomendações de Carvalho (1995) e Sousa (2003) quando assinalam que a participação popular relaciona-se à democratização da saúde e se vincula à reivindicação ao acesso universal e igualitário aos serviços e ao poder. Tem, também, o sentido de luta e contestação, tendo em vista que os problemas relacionados ao mau funcionamento do sistema encontram solução na organização, mobilização, denúncia e pressão, viabilizada pela participação direta de vários segmentos sociais de grupos locais de saúde, vinculados às unidades de prestação de serviços na área.

Visando encontrar respostas possíveis ao problema deste estudo, procuramos analisar a percepção dos conselheiros comunitários de saúde, profissionais e usuários do Programa Saúde da Família acerca da participação popular, perseguindo os seguintes objetivos específicos: identificar o processo de participação dos conselheiros comunitários de saúde na proposição, efetivação e avaliação das ações desenvolvidas pelo PSF; e identificar o nível de participação dos usuários nas ações desenvolvidas pelos grupos educativos do PSF.

\section{Método}

A pesquisa foi estruturada a partir de estudo analítico-descritivo, com abordagem qualitativa. A opção pelo estudo qualitativo parte da compreensão de que ele trabalha com o universo de significados, motiva- 
ções, aspirações, crenças, valores, atitudes dos atores entrevistados, o que corresponde a um espaço mais profundo de relações e dos fenômenos que não podem ser traduzidos à operacionalização de variáveis definidoras dos estudos quantitativos (MINAYO, 1994).

Inicialmente fizemos um levantamento exploratório na Secretaria Municipal de Saúde de Campina Grande a fim de coletar dados acerca das Unidades Básicas de Saúde e delimitar os participantes da pesquisa, bem como formalizar a autorização para proceder tal investigação. Para seleção das unidades de saúde contempladas no estudo, consideramos como requisitos: o tempo de atuação no município, especialmente, aquelas pioneiras, e a existência, em suas áreas de abrangência, de Conselhos Locais de Saúde. Dessa forma, fizeram parte de nossa pesquisa duas Unidades Básicas de Saúde da Família, sendo uma no bairro do Pedregal e outra no Tambor, com seus respectivos Conselhos Locais de Saúde.

Compõe a população de nossa pesquisa o segmento dos conselheiros comunitários com assentos nos Conselhos Locais de Saúde, profissionais das equipes que atuam nas Unidades Básicas do Programa Saúde da Família e usuários dos grupos educativos das respectivas unidades. Tendo em vista a dimensão deste quadro populacional, elegemos uma amostra intencional constituída por sujeitos estrategicamente escolhidos em razão do expressivo papel que ocupam no contexto do estudo em questão, conforme descrição a seguir.

Segmento de profissionais: seis sujeitos, sendo dois assistentes sociais, dois enfermeiros e dois médicos, formando dois grupos de três diferentes profissionais para cada bairro. Como o número dos profissionais que atuam nas equipes do PSF é significativo, estabelecemos critérios para a escolha desse segmento: nível de escolaridade superior; tempo de atuação no programa; profissionais que conduzem o processo metodológico dos grupos educativos e que participam das atividades dos Conselhos Locais de Saúde.

Segmento de usuários: quatro sujeitos dos grupos educativos, sendo dois por bairro. Consideramos pertinente a inserção desse segmento na pesquisa pelo fato dos grupos educativos manterem uma periodicidade de reuniões sistemáticas realizadas no espaço interno das unidades de saúde. Para seleção dos usuários desses grupos, optamos por pessoas que apresentavam, segundo relato dos profissionais das unidades de saúde, uma participação mais efetiva e assídua nos encontros dos grupos, por serem também aqueles que há mais tempo freqüentavam esses serviços.

Segmento de conselheiros: quatro sujeitos com assentos nos Conselhos Locais de Saúde, sendo dois por bairro. Incluímos tal segmento em nosso estudo por considerá-lo, pelo menos em tese, como sujeitos que promovem a participação e o controle social.
Quanto ao critério para escolha dos conselheiros, levamos em conta o expressivo papel que ocupam no âmbito comunitário, enquanto lideranças representativas em movimentos de Associações de Moradores, Sociedade Amigos de Bairros, Clube de Mães, entre outros. Para realizar tal processo, participamos de uma reunião em cada conselho, objetivando solicitar verbalmente aos presentes a disponibilidade em participar da pesquisa, ficando nessa ocasião agendadas as entrevistas.

Utilizamos como instrumente de coleta de dados a entrevista aberta, a qual foi registrada em fitas magnéticas, posteriormente transcritas. Fizemos a análise dos dados através de categorização, estabelecida a partir dos dados fornecidos pelos sujeitos entrevistados, seguindo as etapas do método análise de conteúdo.

Em conformidade com as determinações das Resoluções 196/96 e 251/97 do Conselho Nacional de Saúde, foram cumpridas todas as normas e diretrizes regulamentadoras de pesquisa envolvendo seres humanos. Sendo assim, a presente pesquisa foi submetida à aprovação do Comitê de Ética em Pesquisa da Universidade Estadual da Paraíba. O Termo de Consentimento Livre e Esclarecido foi entregue aos sujeitos que se dispuseram a participar da mesma. Cumprimos, dessa forma, os direitos e deveres da comunidade científica, resguardando a conduta ética no tocante à instituição anfitriã e, principalmente, aos sujeitos da pesquisa. Registramos, ainda, a preocupação em assegurar a não identificação dos sujeitos entrevistados, resguardando a privacidade e o sigilo de suas identidades. Em função disso, optamos por codificar os seus nomes quando da citação de suas falas contidas neste trabalho. Sendo assim, o segmento dos conselheiros foi identificado pela letra C; o dos usuários, pela letra U; enquanto que o dos profissionais, pela letra $\mathrm{P}$.

\section{Resultados}

\section{A participação popular no Programa Saúde da Família: aspectos histórico-conceituais}

A participação popular na gestão da política de saúde encontra seu anteparo na Constituição Federal de 1988 (BRASIL, 2004), que em seus incisos aponta as diretrizes do Sistema Único de Saúde a partir de três eixos: descentralização, atendimento integral e participação comunitária. Esse direito social encontra-se melhor definido na Lei Orgânica da Saúde n. 8.080 e na Lei Complementar n. 8.142, ambas de 1990, sendo que esta última dispõe sobre a participação da comunidade na gestão do SUS (BRASIL, 1990).

Nesse sentido, as três esferas de governo (federal, estadual e municipal) assumiram, a partir de 1994, 
o Programa Saúde da Família (PSF). Evidenciavase no discurso consensual que o modelo de assistência à saúde, centrado na estrutura médico-hospitalar, esgotou suas possibilidades de responder com eficácia à crescente demanda da população. Sendo assim, o PSF foi apresentado pelo Ministério da Saúde como uma estratégia para a mudança do modelo assistencial hegemônico (BRASIL, 1994).

Constitui-se não como um modelo para atender somente regiões pobres e famílias ou comunidades excluídas, embora tenha como parte de suas responsabilidades ajudar a superar as desigualdades no campo da saúde, mas como uma política de fortalecimento dos princípios propostos pelo SUS. Contudo, a prioridade de atendimento do PSF recai em regiões de maior risco social. Para tanto, sua atuação baseia-se na concepção de que as unidades de saúde devem oferecer cuidados de atenção básica à comunidade, aproximando-se dos usuários, estendendo os serviços para as localidades onde não estão disponíveis e introduzindo a assistência à saúde no espaço-domicílio.

Em Campina Grande-PB, o PSF foi implantado em 1994, através da Secretaria Municipal de Saúde, inserido no Plano Municipal de Saúde, de acordo com as prioridades e dados epidemiológicos, como a mortalidade materno-infantil, mortalidade proporcional por doenças infecto-contagiosas e o percentual de crianças que nascem abaixo do peso. A referida cidade foi uma das pioneiras em nível estadual a assinar o convênio. Inicialmente, apenas três bairros foram contemplados: Pedregal (com três equipes mínimas), Mutirão do Serrotão (duas equipes) e Tambor (uma equipe). A partir de 1995, o município implantou o Programa de Agentes Comunitários de Saúde em vários bairros, passando os agentes comunitários de saúde a atuarem de forma integrada com o PSF.

Em todas as Unidades Básicas de Saúde da Família são prestados atendimentos no que se refere a consultas, vacinação, atendimentos de pré-natal, curativos, nebulização, entre outros. Uma das inovações trazidas pelo PSF refere-se à institucionalização de mecanismos que permitem a participação popular e o controle social. Esses mecanismos se consubstanciam tanto na sua co-gestão através da Secretaria Municipal de Saúde, Conselho Municipal de Saúde e Conselho Local de Saúde, quanto na própria metodologia e seu processo de trabalho.

A aproximação com a população se processa através de várias estratégias, que vão desde a abordagem diferenciada no cuidado individual até o incremento das reuniões e práticas socioeducativas com os grupos de usuários e com a própria comunidade. Dentre as estratégias de aproximação destacam-se a visita domiciliar, pelo importante contato com as famílias e a reunião mensal com os Conselhos Locais de Saúde, compostos por representações exis- tentes na comunidade e representantes da Unidade Básica de Saúde da Família.

A proposta de construção do modelo assistencial, centrado nas estratégias de implementação do PSF, deve estar em consonância com os princípios do Sistema Único de Saúde. Nessa perspectiva, a proposta de ações de saúde voltadas à família pressupõe:

[...] o reconhecimento da saúde como um direito de cidadania e que expressa a qualidade de vida; a eleição da família e de seu espaço social como núcleo básico de abordagem no atendimento à saúde; a democratização do conhecimento do processo saúde/doença; a organização dos serviços e da produção da saúde; a intervenção sobre os fatores de risco aos quais a população está exposta; a prestação de atenção integral, contínua e de boa qualidade nas especialidades básicas de saúde à população adscrita, no domicílio, no ambulatório e no hospital; a humanização das práticas de saúde da comunidade; 'o estímulo à organização da comunidade para o efetivo exercício do controle social'; o estabelecimento de parcerias buscando desenvolver ações intersetoriais (CORDEIRO, 1996, p. 13, grifo nosso).

O PSF estimula a criação em nível microrregional de Conselhos Locais de Saúde ligados às unidades de saúde. No bojo de tal proposição, a participação popular deve assumir amplitudes maiores estendendo-se a outras manifestações de garantia de direito à saúde, não apenas aos canais legalmente instituídos. Nesse sentido, concordamos com Péret (2001, p. 221) ao assinalar que:

O conceito de participação social requer uma ampliação, assim como sua magnitude, pois esta não se limita apenas aos canais institucionais tradicionais. Aos profissionais de saúde cabe o desafio de romper com o ranço das antigas políticas, que excluíam o cidadão dos serviços públicos de saúde, voltando-se para busca de uma participação ampla e não seletiva que apropria apenas aqueles sujeitos afinados com os costumeiros jargões institucionais.

Os Conselhos Locais de Saúde foram idealizados como formas de participação popular, onde os profissionais e a comunidade possam discutir sobre as questões de seus interesses, bem como elaborarem propostas a serem levadas e defendidas em instâncias decisórias, a exemplo dos conselhos e conferências municipais de saúde. Trata-se, portanto, de um espaço potencializador da criatividade dos usuários na proposição e elaboração da política local de saúde, já que são eles os que realmente vivenciam no cotidiano das unidades de saúde a efetividade ou não 
das políticas. Assim, os Conselhos Locais de Saúde, embora não previstos na forma da Lei Federal n. 8.142/90 podem ser traduzidos como possibilidade de ampliação da participação comunitária na fiscalização, proposição e execução da política de saúde. Para Bravo (2001, p. 133), o Conselho Local de Saúde é

[...] uma entidade não instituída jurídico e legalmente, mas que possibi-

lita a participação da comunidade na elaboração de propostas para a política de saúde em sua localidade; consiste na articulação dos usuários e dos trabalhadores de saúde, com a finalidade de estabelecer relação entre conselheiros e a base.

Além da formação dos Conselhos Locais de Saúde, o PSF traz em sua proposta de trabalho ações contínuas no processo de educação e informação em saúde, visando atender às necessidades dos problemas sociais vivenciados pelos usuários. Dentro dessa dinâmica, destacam-se as práticas dos grupos educativos, direcionados para atender os usuários que se encontram em situação de risco, visando também atender às suas necessidades sociais. Esses grupos são caracterizados pela substituição da demanda espontânea pela demanda programada, isto é, são estrategicamente formados com um objetivo determinado, seja por patologia, por faixa etária, ou por algum trabalho que a equipe queira realizar a partir da demanda posta pela comunidade. Em sua maioria, os grupos educativos são os de gestantes, crianças desnutridas, diabéticos, aleitamento materno, adolescentes, hipertensos, idosos, saúde mental, planejamento familiar.

\section{A participação dos conselheiros comunitários de saúde na gestão local do PSF}

Os Conselhos Locais de Saúde passam a assumir importância no cenário político dos movimentos comunitários de Campina Grande ao serem identificados como mecanismos de fortalecimento do controle social na gestão local do PSF. Esses espaços trazem uma significativa relevância para as comunidades, com vistas ao envolvimento da população não somente nas questões específicas no campo da saúde, bem como nos demais problemas dos bairros.

Em tese, os Conselhos Locais de Saúde destacam-se por seu caráter democrático, na medida em que é permitido a todo e qualquer cidadão participar de suas reuniões com direito a voz. Tal aspecto per- mite a presença de outras pessoas da comunidade (políticos, trabalhadores, dentre outros) que expressam suas reivindicações e/ou necessidades dos bairros, além de lideranças comunitárias que habitualmente participam das reuniões. É freqüente nas reuniões a presença de segmentos da comunidade, principalmente daqueles que sofrem carências básicas ligadas às questões de saúde. Dessa forma, os comunitários inserem-se nessas instâncias como legítimos portavozes das necessidades, afirmando o caráter popular de sua participação, na medida em que sua representação encontra respaldo na comum condição de vida das demais pessoas locais. Assim, a participação dos comunitários pode significar a possibilidade real de inscrever suas demandas nas prioridades dos bairros, além de torná-los membros efetivos dos conselhos.

Em Campina Grande, a formação dos Conselhos Locais de Saúde esteve bastante articulada à estruturação das Unidades Básicas de Saúde da Família, estratégia adotada, em conformidade com os preceitos do SUS, para possibilitar canais de participação popular na gestão do PSF. A esse respeito, os depoimentos abaixo são emblemáticos, sinalizando que o PSF traz em sua metodologia de trabalho o incentivo à participação social, particularmente na adequação das ações de saúde às necessidades da comunidade, visando contribuir para reorganização das práticas de trabalho a partir da atenção básica.

O Conselho Comunitário de Saúde foi criado no bairro justamente com a formação do Saúde da Família. Um dos pilares do Saúde da Família é o controle social, é a participação popular. E a gente, chegando aqui, começamos a colocar mais um desses pontos pra serem implementados. E aí o conselho nasce junto com o Saúde da Família, evidentemente aproveitando o que o bairro já tinha de organização, tentando aglutinar Clube de Mães, SABs ${ }^{1}$ [...]. O Saúde da Família tem um espaço privilegiado pra desenvolver essas ações, porque a gente já tem como princípio a participação popular como ponto fundamental pra desenvolver, pra que a gente possa avançar (P1, 13 jul. 2004).

O Conselho tem uma ligação muito grande com o PSF, porque ele foi criado a partir do momento em que o PSF chegou nessa comunidade. Todo mês a gente discute todos os problemas do posto de saúde, da comunidade, a gente já leva pra reunião de conselho. Acompanha a falta da questão de medi- 
cação, material de curativo e dos demais problemas do bairro (P5, 4 ago. 2004).

Com relação à participação dos conselheiros comunitários nas proposições e efetivações de ações desenvolvidas no âmbito do PSF, as falas dos citados conselheiros sinalizaram para o bom nível de capacidade propositiva e interventiva dos mesmos, tanto referente aos serviços prestados pelas equipes nas unidades de saúde, quanto às questões de infra-estrutura dos bairros. Dentre as proposições dos conselheiros, destacamos as seguintes:

a) implantação de novas unidades de saúde da família, aumentando progressivamente o número de equipes nos bairros;

b) projeto de urbanização e saneamento básico do bairro Pedregal, com o aproveitamento da mão-de-obra das pessoas que residem na comunidade;

c) criação de uma escola de segundo grau para o bairro Tambor;

d) reformas nas unidades de saúde dos dois bairros Pedregal e Tambor;

e) aquisição de gabinetes odontológicos na unidade do PSF do Pedregal;

f) aumento da quantidade de medicação nas unidades de saúde para suprir a demanda comunitária;

g) tráfego de ônibus dentro dos bairros;

h) não obrigatoriedade de moradia dos agentes comunitários de saúde nas suas áreas de atuação.

Apesar dessas propostas, os conselheiros apontaram fatores que fragilizam os Conselhos Locais de Saúde na condução e consolidação de suas intervenções na gestão local do PSF, quais sejam:

a) dificuldade em estabelecer canais de interlocução e articulação com os comunitários, referendada pela falta de uma maior participação da comunidade nos referidos conselhos;

b) não atendimento por parte do gestor municipal às solicitações dos conselheiros referentes à maior quantidade de medicamentos básicos para suprir a toda demanda comunitária, bem como à implantação de gabinete odontológico para o bairro Pedregal;

c) pouca atenção dispensada pelos conselhos para o engajamento de outras entidades comunitárias nas suas atividades, como escolas e estabelecimentos comerciais, dificultando a aproximação e o envolvimento da comunidade;

d) falta de um processo de capacitação permanente tanto para profissionais, como para conselheiros.

Quanto a este último item, abordado pelos conselheiros, reportamo-nos ao assinalado por Bravo
(2001): para se efetivar a participação popular, no sentido de viabilizar a democratização na saúde, é necessário promover capacitações e assessorias permanentes, tanto para conselheiros, quanto para profissionais de saúde, na perspectiva de fortalecer o projeto democrático nessa área.

As análises dos profissionais das Unidades Básicas de Saúde da Família, em relação à participação dos conselheiros comunitários na gestão local do PSF, também destacaram as seguintes limitações:

a) a não participação dos comunitários representantes dos Conselhos Locais de Saúde no planejamento das ações internas desenvolvidas pelas equipes do PSF;

b) as avaliações dos conselheiros, quanto ao trabalho prestado pelo PSF, feitas semestral e anualmente, serem baseadas apenas nas informações que as equipes passam para os conselhos, referendadas pelos indicadores de resultados alcançados pelo programa.

Por outro lado, os profissionais expressaram avanços no processo participativo dos conselheiros comunitários, referendados a seguir:

a) o bom nível de participação dos conselheiros no processo de proposição e intervenção nos problemas gerais dos bairros;

b) a presença dos Conselhos Locais de Saúde como instrumentos bastante significativos para a construção de uma nova forma de se trabalhar a saúde, especificamente no tocante ao processo de organização e mobilização da comunidade em torno não somente da discussão e encaminhamentos de questões específicas no campo da saúde, mas em todos os demais problemas existentes no espaço comunitário.

Consideramos, a partir das propostas arroladas pelos conselheiros, que a dinâmica de funcionamento dos Conselhos Locais de Saúde faz emergir elementos constitutivos de um espaço democrático na medida em que os representantes da comunidade travam debates que desencadeiam processos de enfrentamentos e reivindicações junto ao gestor público, viabilizando na prática o objetivo da construção da participação popular. Vale salientar que estes conselhos são considerados como o locus para onde converge boa parte das demandas da comunidade em busca de possíveis soluções junto aos órgãos competentes. Nessa perspectiva, Cordeiro (1996) enfatiza que o reconhecimento da saúde como um direito de cidadania está estritamente associado às formas de organização política da comunidade para o efetivo exercício do controle social. Da mesma forma, Campos (1997) aponta que os sujeitos desses espaços podem contribuir efetivamente tanto na defesa do movimento sanitário, apostando na participação popular como direito de cidadania, quanto como um mecanismo útil à reforma do sistema de saúde. 


\section{A participação dos usuários nas ações desen- volvidas pelas equipes nas UBSF}

Em relação à participação dos usuários tanto no que diz respeito às questões relacionadas aos grupos educativos, quanto aos problemas existentes na comunidade, as respostas dos profissionais variaram. Em menor incidência encontramos discursos que apontaram como de bom nível, pelo fato de os comunitários manterem assiduidade nas reuniões, como também indicarem proposições para o desempenho das atividades dos grupos e para os demais problemas da comunidade. Em maior incidência ressoaram respostas que consideraram essa participação incipiente. Vejamos o que expressam os profissionais que avaliaram positivamente a participação dos usuários:

Olha, a gente considera esses grupos de uma boa qualidade, de boa participação. Quando a gente começou com os grupos, a comunidade, aqui, não tinha... antes do PSF, essa prática de reuniões, de se reunir, de discutir, de dialogar (P5, 4 ago. 2004).

Basta dizer que a gente tinha mulheres que não saíam de casa, que nunca tinham participado de nenhum trabalho social. Na medida que elas começam a vir e são escutadas... (não vêm para ser um mero expectador, mas para participar, sugerir.... começan a dar contribuição, que avalia, que vai mudando). É um próprio processo terapêutico. $\mathrm{Na}$ medida que você fala, você também vai criando... é... você vai se criando gente, vai se tornando uma pessoa capaz de dar opinião, de ser escutada (P1, 13 jul. 2004).

Todavia, a maioria dos profissionais avalia a participação dos usuários nos grupos educativos de forma tímida e lenta, especialmente no sentido deles sugerirem ações e temáticas a serem trabalhadas nas oficinas. Reconhecem certa acomodação dos usuários quanto ao encaminhamento das atividades nos grupos, esperando que a equipe direcione os trabalhos. Nas transcrições abaixo, podemos perceber com bastante evidência essa questão:

Acho que tem uma participação razoável, [...] própria participação da população, dos usuários de se sentirem sujeitos do seu processo é uma coisa ainda muito... muito lenta. (P1, 13, jul. 2004).

A gente ainda encontra, assim, um pouquinho de dificuldade na questão deles darem sugestões [...] Porque toda vida eles dizem: 'Não, o que vocês trouxeram é bem-vindo'. Raramente eles sugerem... (P5, 4 ago. 2004).
Eu considero ainda o nível de participação baixo ou pequeno [...] há usuários que já despertaram essa consciência e outros ainda não... Porque a gente quer que os usuários tenham uma participação consciente, que venha contribuir tanto no aspecto propositivo quanto no participativo de nossas ações (P4, 11 ago. 2004).

Os profissionais pontuaram alguns fatores que inibem ou dificultam a participação dos usuários nos grupos educativos:

a) a grande quantidade de pessoas nos grupos, horários e periodicidade das reuniões;

b) a falta de recursos materiais para se trabalhar as oficinas;

c) a falta de infra-estrutura e locais adequados para se fazer reuniões com a comunidade;

d) a falta de um processo de capacitação permanente da equipe profissional;

e) o baixo nível de desenvolvimento socioeconômico da comunidade, referendado pela carência de projetos de inclusão social, associado também ao fato de que as pessoas não têm historicamente construído esse hábito de participar politicamente dos problemas gerais da comunidade.

Apesar das limitações antes identificadas, os profissionais indicaram que o PSF vem adotando em seu processo de trabalho inovações metodológicas que contemplam níveis e formas de participação mais efetivas dos usuários, o que para alguns se traduz em propostas de avanços nas ações do programa.

Constatamos a preocupação dos profissionais em manter o pleno funcionamento desses grupos, caracterizados como prioritários para o desenvolvimento das ações do programa, na medida em que esses espaços permitem trabalhar a educação permanente no processo saúde-doença na perspectiva de prevenção e promoção da saúde, e na construção do exercício de práticas participativas.

Contrastando com a maioria dos discursos dos profissionais em relação à participação dos usuários nos grupos educativos, verificamos que a totalidade das falas apresentadas pelos usuários evidencia sua participação nas atividades operacionalizadas nos grupos educativos, na medida em que freqüentam assiduamente as reuniões, escutam, discutem, lançam propostas e emitem opiniões para o bom desempenho do trabalho. A adoção dessa atuação inscreve-se nos seguintes depoimentos:

A gente ouve, discute, participa para que melhore. A gente faz esse trabalho, tanto de ouvir, receber, dar e receber [...] Quando a gente quer outro artesanato, a gente já discute, já leva o consenso, já vem outra pessoa pra ensinar. É ótimo. É muito bom (U4, 24 ago. 2004). 
Uma das sugestões que deu certo foi a do encontro de casais [...] E outra sugestão foi atividades de crochê, pintura. Outra sugestão é que antes o grupo se reunia todo numa vez só durante o mês. Num dia só. Mas aí a gente sugeriu que dividisse o grupo (U1, 19 ago. 2004).

Os discursos dos usuários sinalizam ainda que, dentro das possibilidades do PSF, as propostas advindas do segmento dos grupos educativos são acatadas pelos profissionais. Essas proposições são fruto do processo de participação experimentado pelos sujeitos que se engajaram nos referidos grupos traduzindo-se no contributo para a melhoria das ações do PSF. Vejamos algumas propostas apontadas pelos usuários:

a) resolver a questão da falta de medicamentos nas unidades de saúde;

b) proporcionar a divisão dos grupos numerosos em sub-grupos, facilitando a participação de seus integrantes;

c) partir para a formação de novos grupos, como os vinculados a atividades artesanais e grupos de casais;

d) encontrar o espaço físico adequado para a realização das reuniões.

Percebemos, ainda, que os usuários desses grupos expressam avanços no tocante ao reconhecimento dos benefícios trazidos pelo PSF, especialmente os relacionados às ações dos grupos educativos que promovem o resgate da auto-estima, além do bom atendimento e acolhimento prestado pelas equipes:

Todo mundo participa. Essa participação, ela é construída no nosso dia-a-dia, lá com elas. O mais importante disso tudo é o atendimento que o PSF faz aqui na comunidade [...]. O atendimento é excelente. A gente chega lá, às vezes cheia de problema na cabeça e sai, olhe, sem nenhum. $\mathrm{O}$ atendimento não precisa daqueles choques, está entendendo? que dão nesses hospitais por aí. É ótimo, é maravilhoso (U3, 27 ago. 2004).

Os discursos dos entrevistados indicam que os grupos educativos são espaços onde os usuários conseguem expressar suas falas, atingindo uma dinâmica de discussão em torno de seus desejos e anseios e, ao mesmo tempo, compreendendo que o elemento da participação nas ações desenvolvidas pelo PSF é um caminho a ser trilhado, construído. Nessa perspectiva, Vasconcellos (1998) ressalta a importância da participação da comunidade nos serviços e ações de saúde, em particular, a experiência desenvolvida pelo PSF, do ponto de vista da construção do conceito de saúde como melhoria de qualidade de vida.

\section{Discussão}

Quando analisamos o desenvolvimento histórico das políticas de saúde no Brasil, deparamo-nos com uma realidade conflitante, marcada por uma forte tendência de autoritarismo e centralismo do poder estatal no enfrentamento das epidemias coletivas. O Estado caracterizava-se como portador exclusivo da verdade técnica e do poder decisório. A participação da população nesse processo, segundo Carvalho (1995), não chegou nem a ser passiva. A partir da implementação do SUS, o princípio da participação constitui-se como direito de cidadania. Representa um dos traços diferenciadores do SUS para a garantia plena de sua consolidação.

Podemos inferir que os grupos educativos agregam várias pessoas da comunidade com vistas ao enfrentamento do processo saúde-doença, configurando-se como espaços para o trabalho de promoção e prevenção da saúde, permitindo possibilidades de avanços na perspectiva de participação popular dos sujeitos que deles tomam parte, traduzindo-se na melhoria das ações desenvolvidas pelo PSF. Essa mudança de intervenção nos remete a considerar que os depoimentos apresentados nas falas dos usuários dos grupos educativos apontam para a construção de um novo modelo de assistência à saúde das pessoas nas comunidades, sobretudo nos aspectos referentes ao acesso aos serviços, à escuta e ao acolhimento por parte dos profissionais das equipes. Os Conselhos Locais de Saúde são destacados como instrumentos bastante significativos para a construção de uma nova forma de se trabalhar a saúde, especificamente no tocante ao processo de organização e mobilização da comunidade, em torno não somente da discussão e encaminhamentos de questões específicas, mas em todos os demais problemas existentes no espaço comunitário, permitindo possibilidades de participação da comunidade.

Consideramos que o processo de participação na gestão local do PSF, nas duas localidades de Campina Grande, vem sendo modificado na medida em que os comunitários ocupam os espaços de participação. Colocamos em evidência as afirmações contidas em boa parte das falas de dois segmentos (conselheiros 
e usuários), apontando a existência de proposições dos conselheiros e usuários para a melhoria dos serviços e ações locais de saúde.

É possível considerar que os grupos educativos e os Conselhos Locais de Saúde vêm sendo construtores da participação popular no campo da saúde na medida em que os conselheiros comunitários e os usuários desses grupos têm elaborado proposições e efetivado ações para a melhoria dos serviços e ações locais de saúde. Isso, de certa forma, nos leva a entender que o PSF vem se constituindo como uma das estratégias de reestruturação da atenção básica dos serviços de saúde, traduzindose num campo fértil para a implementação da participação popular.

\section{Referências}

BRASIL. Constituição da República Federativa do Brasil de 1988, com as alterações adotadas pelas Emendas Constitucionais 1/92 a 44/2004 e pelas Emendas Constitucionais de Revisão n. 1 a 6/94. Brasília: Senado Federal, Subsecretaria de Edições Técnicas, 2004.

Coordenação da saúde na comunidade. Programa Saúde da Família - saúde dentro de casa. Brasília: Ministério da Saúde, 1994.

Lei Orgânica da Saúde, n. 8.080 e n. 8.142/90. Sistema Único de Saúde. Brasília: Ministério da Saúde, 1990.

BENEVIDES, M. V. Democracia e cidadania. In: VILLASBÔAS, R. (Org). Participação popular nos governos locais. São Paulo: Polis, 1994.

BRAVO, M. I. S. Participação social e controle social . In:_____; MATOS, M. C. de; ARAÚJO, P. S. X. de. (Org.). Capacitação para conselheiros de saúde - textos de apoio. Rio de Janeiro: UERJ/NAPE, v. 1, p. 77-84, 2001.

CAMPOS, G. W. de S. Reforma da reforma: repensando a saúde. São Paulo: HUCITEC, 1997.

CARVAlHO, A. I. de. Conselhos de saúde no Brasil. Participação cidadã e controle social. Rio de Janeiro: FASE, 1995.

CORDEIRO, H. O PSF como estratégia de mudança do modelo assistencial do SUS. Cadernos Saúde da Família, n. 1, Brasília, Ministério da Saúde, 1996.

MERHY, E. E.; FRANCO, T. B. Programa Saúde da Família: somos contra ou a favor? Revista Saúde em Debate, Rio de Janeiro: CEBES, v. 26, p. 118-122, n. 30, 2002.
MINAYO, M. C. de S. O desafio do conhecimento: pesquisa qualitativa em saúde. São Paulo, Rio de Janeiro: HUCITEC, ABRASCO, 1994.

PÉRET, T. C. O Programa Saúde da Família: questões e perspectivas. A experiência desenvolvida no Município de Campina Grande-PB. Dissertação (Mestrado em Serviço social) - Pontifícia Universidade Católica do Rio de Janeiro (PUCRJ). Rio de Janeiro, 2001.

SOUSA, R. M. S. Controle social em saúde e cidadania. Revista Serviço Social \& Sociedade, São Paulo: Cortez, n. 74, p. 3-200, 2003.

VASCONCELLOS, M. P. Reflexões sobre a saúde da família: aprendendo com projetos de saúde pública em dois municípios brasileiros. In: MENDES, E. V. (Org.). A saúde no nível local. São Paulo: HUCITEC, 1998, p. 155-172.

\section{Nota}

1 Sociedade Amigos de Bairro

\section{William Almeida de Lacerda}

Mestre em Políticas Sociais pela Universidade Estadual da Paraíba (UEPB)

Assistente Social da Estratégia Saúde da Família de Campina Grande

Professor substituto do Departamento de Serviço Social da UEPB.

\section{Idalina Maria Freitas Lima Santiago}

Doutora em Ciências Sociais pela Pontifícia Universidade Católica de São Paulo (PUCSP)

Professora convidada do Programa Regional de

Pós-Graduação em Desenvolvimento e Meio Ambiente da Universidade Federal da Paraíba (UFPB) e UEPB

Professora titular do Departamento de Serviço Social e do Mestrado Interdisciplinar em Ciências da Sociedade, na UEPB

Endereço

Curso de Serviço Social da UEPB

Rua Antônio Guedes de Andrade, 114, Catolé

Campina Grande - Paraíba

CEP: 58104-410 